\title{
Maternity and Paternity Policies Available to Academic Librarians
}

\author{
Ruth Sara Connell
}

This study examines how frequently parental leave and other related childcare policies are available to academic librarians across the United States. It also looks at the relationships between policies offered and types of academic libraries that offer those policies. The author surveyed administrators at academic libraries serving baccalaureate, master's, and research institutions and discovered that benefits available to academic librarians are not as generous as those available to faculty, and that tenured and tenure-track librarians fare better than counterparts who are not eligible for tenure.

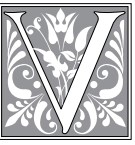

ery few studies have been published regarding parental policies for academic librarians after the birth or adoption of a child. This is surprising given that librarianship is a field dominated by women, ${ }^{1}$ and childcare leave and other related policies disproportionally affect women. To learn more about policies available to academic librarians, the author surveyed administrators within academic libraries.

The research objectives of this study were to discern how frequently various parental policies are offered to academic librarians at four-year colleges and universities across the United States; to determine whether there are differences between parental polices offered to librarians, faculty, and other campus staff; to determine whether there are differences between types of institutions regarding parental policies offered to librarians; and to discover whether there are differences between policies available to academic librarians based on whether they are at institutions offering librarians faculty or tenure status.

Throughout this study, the phrase academic librarians refers to all librarians working in four-year colleges and universities regardless of tenure/faculty status. The term faculty is used to refer to faculty outside the library (excluding academic librarians with faculty status).

\section{Literature Review}

There are very few published studies regarding parenthood and academic librarianship and none specifically surveying family-friendly policies offered in academic libraries. While specific to tenure-track librarians, one study offered a hypothesis to explain this lack of literature on the subject. "Perhaps the controversial nature of tenure in librarianship is to blame... If the profession cannot agree on the issue of faculty status for librarians,

Ruth Sara Connell is Associate Professor of Library Services and Electronic Services Librarian at Valparaiso University; e-mail: Ruth.Connell@valpo.edu. Thanks to Drs. Fred and Tschera Connell for their helpful comments and feedback on earlier versions of this paper. (C2013 Ruth Sara Connell, AttributionNonCommercial (http://creativecommons.org/licenses/by-nc/3.0/) CC BY-NC 
it is unlikely to turn its attention toward issues such as balancing tenure requirements and parenthood." 2

Stephanie J. Graves, Jian Anna Xiong, and Ji-Hye Park's particularly relevant article surveyed tenured and tenure-track librarians in Association of Research Libraries about the relationship between the promotion and tenure $(\mathrm{P} \& \mathrm{~T})$ process and parenthood. ${ }^{3}$ The article addressed the differences between academic librarians and other subject faculty members and how librarians felt P\&T affects parenting. The authors argued that it "would be unwise to rely on studies of tenure status and parenthood undertaken by other disciplines, since the workload and environment of academic librarianship are so often different from that of other academic disciplines." ${ }^{\prime 4}$ Some of their respondents illustrated this idea by pointing out the difference between a twelve-month, fortyhour workweek that most academic librarians follow in contrast with the nine-month more flexible schedule our counterparts in other departments enjoy. ${ }^{5}$ While this study focused on the difference between tenured/tenure-track librarians and faculty, a large group of academic librarians was excluded: those who are not tenuretrack. This exclusion makes it difficult to extrapolate the results of this Graves et al. study to make generalizations about policy norms within academic libraries.

Another study surveyed female academic library directors to discover how career goals have affected motherhood and vice versa. ${ }^{6}$ The majority $(64.8 \%)$ of directors with children responded that "motherhood did not influence their advancement," and most felt they had reached their career goals. When asked to list the factors that contributed to their success, the most commonly cited reason was a helpful partner, while "benefits such as maternity leave, paid or otherwise, were not factors." In fact, only 56 out of 219 director mothers reported taking leave. ${ }^{7}$

A number of articles, not specific to the field of librarianship, addressed parental leave for faculty in higher education.
A foundational study for this paper was authored by the University of Michigan's Center for the Education of Women and entitled "Family-Friendly Policies in Higher Education." The authors conducted two similar surveys, the first in 2002 and the second in 2007, in which they asked representatives from a random sampling of institutions across the United States about their family-friendly policies for faculty. They discovered that during the five years between the two studies, benefits offered had increased. ${ }^{8}$

The University of Michigan studies also found that, although some institutions offer codified, formal familyfriendly policies, many institutions offer these policies on an ad hoc or informal basis. ${ }^{9}$ The 2007 study, for example, found that 36 percent of responding institutions offered institutionwide and formally written policies offering paid time off for new biological mothers after the period of disability, but this number increased to 49 percent of institutions when ad hoc and informal practices were included. ${ }^{10}$ The most frequently offered policy was paid time off for new biological mothers during the period of disability. ${ }^{11}$

One organization that has been addressing issues related to faculty work load and family responsibilities for years is the American Association of University Professors (AAUP). In 1974, it called for flexibility, including "availability of such alternatives as longer-term leaves of absence, temporary reductions in workload with no loss of professional status, and retention of full-time affiliation throughout the child-bearing and child-rearing years." ${ }^{12}$ More recently, as an organization that advocates for academics, it has argued for "institutions to offer significantly greater support for faculty members and other academic professionals with family responsibilities." ${ }^{13}$ The organization specifically mentions support for policies such as tenure clock stoppage, paid disability leaves for pregnancy, paid familycare leave including same-sex or domestic partners, and active service with modified 
duties. ${ }^{14}$ Active service with modified duties refers to reduced teaching and departmental responsibilities for faculty, but with full pay. The AAUP policy lists the University of California system as an organization modeling this policy. Their “'active service-modified duties' policy allows faculty partial or full relief from teaching for one quarter (or semester) if the faculty member has 'substantial responsibility' for care of a newborn or newly adopted child under the age of five" at full pay. ${ }^{15}$

An idea that recurred in the literature was that, even when family-friendly policies are available, faculty often do not inquire about or take advantage of these policies. ${ }^{16}$ In a 2006 article, a team of researchers from Pennsylvania State defined "bias avoidance (BA) strategiesbehaviors designed to escape potential career penalties associated with caregiving commitments." 17 The authors described the stereotypical ideal worker as someone who puts in long hours at her or his job with only minimal breaks, suggesting that tenure-track faculty aspire to be or appear to be this ideal worker to earn tenure. Faculty may be afraid to ask for family-friendly policies available to them because they "cannot ask about the relevant parameters without admitting that caregiving plays or will play a central role in their lives - thereby inviting the very career penalties they strive to escape."18

Another recurring theme was the importance of clear and written documentation concerning family-friendly policies. ${ }^{19}$ Joseph Untener, associate provost at the University of Dayton, argues that "academic administrators and female faculty should not have to 'negotiate' about a leave. Such individualized approaches lead to extensive variance among cases that can ultimately result in ill will and even legal liability." ${ }^{20}$ He goes on to state that such negotiated arrangements can make it difficult for department chairs to manage their departments' courses while simultaneously maintaining friendly relationships with faculty members. ${ }^{21}$

\section{Methodology}

To gather a representative sample of colleges and universities, a proportional stratified random sampling of institutions was culled from the 2010 Carnegie Classification of Institutions of Higher Education lists. $^{22}$ To reach approximately 15 percent of each type of higher education institutions (excluding Associate's Colleges), the following basic classification category lists were downloaded: Research Universities (very high research activity), Research Universities (high research activity), Doctoral/Research Universities, Master's Colleges and Universities (larger programs), Master's Colleges and Universities (medium programs), Master's Colleges and Universities (smaller programs), Baccalaureate Colleges - Arts \& Sciences, and Baccalaureate Colleges-Diverse Fields. Once these eight files were downloaded, every seventh institution on the list was selected for inclusion in the study, resulting in a sample size of 248 institutions.

To determine the recipients of the study, a web search was conducted for each institution to determine who might be the best contact. Some of the larger libraries employed human resources or personnel directors, and, when available, people in these positions were the first-choice recipients. For all the rest of the libraries, someone in administration was chosen for inclusion. If information regarding the administrator's position was given indicating they specifically dealt with personnel issues, they were chosen. When no information was given, the default recipient was the person in the director or dean of libraries position. In some cases, when information was not easily accessible through a library's website, virtual reference was used to contact the library to ask for the best recipient. Once the recipient was selected, his or her e-mail address was located on the institution's library website. During this process, four for-profit academic institutions were eliminated from inclusion because they had no publicly available library website, and a fifth was eliminated because there was no 
e-mail address listed on its site. After those institutions were dropped, a distribution list of 243 institutions remained.

The content of the survey was greatly informed by the literature review and, in particular, the study authored by the University of Michigan's Center for the Education of Women. ${ }^{23}$ Once approved by Valparaiso University's Institutional Review Board, the survey was posted online using web-based survey software. The survey used question logic, in which respondents were routed to different questions based on their answers to previous questions. For example, only those respondents who said librarians were tenure-track at their institutions saw follow-up questions regarding tenure policies.

Another survey design decision was to ask participants to list their institution names. The author needed this information to correlate family-friendly policies by type of institution. All participants were told that the results would be reported in aggregate and that personalized information would be removed before distribution.

The survey was first distributed on July 28, 2011, and, to encourage responses, two incentives were offered. First, all respondents who completed the survey were given the chance to enter a drawing for a $\$ 100$ gift certificate. This drawing was administered by the web-based survey software (for a fee). Second, those interested in the results could opt in to receive them. Two reminders were sent to the distribution list, although those who had identified themselves by opting in to receive results did not receive reminder e-mails. The survey closed on August 25, 2011. Representatives of 82 institutions responded to the survey, although one response had to be eliminated because the respondent did not answer the institutional affiliation question. That left 81 valid responses for a 33 percent response rate.

\section{Demographic Profile of Respondents}

Of the 81 valid responses, 51 (63\%) came from respondents representing private institutions while 30 (37\%) represented public universities and colleges. Broken down into basic Carnegie classification categories, the responses came from the following types of institutions: 14 (17\%) from Research (Very High, High, or Doctoral), 35 (43\%) from Master's (Large, Medium, or Small), and 32 (40\%) from Baccalaureate (Arts and Sciences or Diverse).

When asked whether librarians at their institution were considered faculty, $42(52 \%)$ were and $31(38 \%)$ were not. The remaining eight $(10 \%)$ answered "other," with half of those specifying that some librarians at their institution were considered faculty while others were not.

With regard to tenure, 23 (28\%) of the respondents represented institutions where librarians were tenure-track, and $51(63 \%)$ did not. Of those seven $(9 \%)$ who answered "other," three said they had continuing status, and another three said that tenure-track positions were held by some librarians, but not others.

Because the "other" categories within faculty and tenure status were not of interest to the purposes of this study (for example, it did not matter how many "other" librarians had paid leave for fathers available to them), and because there were too few of these responses to determine with confidence relationship with benefits, those responses were not included in the statistical analysis for faculty and tenure status.

\section{Statistically Significant Results}

A Chi-square test was used to determine the significance of the relationship between institutions' benefits and their demographic data. The independent variables used for demographics were public vs. private institution, basic Carnegie Classification, faculty status for librarians, and tenure status for librarians. There was a small group of significant results. Many of the relationships between demographics and types of benefits available were not significant and are not presented here. Since not all questions were required and 


\begin{tabular}{|l|r|c|c|c|}
\hline \multicolumn{5}{|c|}{ TABLE 1 } \\
\multicolumn{5}{|c|}{ Paid Leave for Biological Mothers During the Period of Disability } \\
by Librarian Tenure Status* \\
\hline & & Not Tenure Track & Tenure Track & Total \\
\hline No Paid Leave & Freq. & 20 & 2 & 22 \\
\hline & $\%$ & $40.0 \%$ & $10.0 \%$ & $31.4 \%$ \\
\hline Paid Leave & Freq. & 30 & 18 & 48 \\
\hline & $\%$ & $60.0 \%$ & $90.0 \%$ & $68.6 \%$ \\
\hline Total & Freq. & 50 & 20 & 70 \\
\hline & $\%$ & $100.0 \%$ & $100.0 \%$ & $100.0 \%$ \\
\hline $\begin{array}{l}\text { Chi-square }=5.966, \mathrm{df}=1, \mathrm{p}=.015 \\
\text { *Excludes responses where the librarian tenure status was classified as “other" }\end{array}$ \\
\hline
\end{tabular}

some respondents only saw a portion of the questions, the number of responses per question varies.

Respondents were asked whether biological mothers were paid during the period of disability; the Family and Medical Leave Act (FMLA) only requires unpaid leave. ${ }^{24}$ Most institutions, 53 out of $77(69 \%$, or $48 / 70$ when institutions where respondents listed "other" under tenure status were excluded, also 69\%), did offer paid leave. But at the 20 institutions where librarians were tenured or tenure-track, 18 $(90 \%)$ offered paid leave (see table 1$)$. A Chi-square test rejects the null hypothesis that the option for paid leave is independent of tenure status: at a significance level of $p=.015$, institutions that grant tenure to librarians are more likely to offer librarians paid maternity leave.

Regarding dependent care leave for mothers, paid or unpaid, beyond the 12 weeks mandated by FMLA, tenured or tenure-track librarians were more likely to have extended leave available to them than librarians without tenure status (see table 2). Of the 76 respondents who answered this question, 32 (42\%) represented institutions where extended leave was not available, 30 (39\%) offered extended leave, and the rest answered "other." (When institutions where respondents listed "other" under tenure status were excluded, the total number was 69 , with 30 , or 43 percent, with no extended leave and 27 , or 39 percent, with extended leave.) Of the

\begin{tabular}{|c|c|c|c|c|}
\hline \multicolumn{5}{|c|}{$\begin{array}{c}\text { TABLE } 2 \\
\text { Dependent Care Leave for Mothers Beyond FMLA } \\
\text { by Librarian Tenure Status* }\end{array}$} \\
\hline & & Not Tenure Track & Tenure Track & Total \\
\hline \multirow[t]{2}{*}{ Offered } & Freq. & 14 & 13 & 27 \\
\hline & $\%$ & $28.0 \%$ & $68.4 \%$ & $39.1 \%$ \\
\hline \multirow[t]{2}{*}{ Not Offered } & Freq. & 27 & 3 & 30 \\
\hline & $\%$ & $54.0 \%$ & $15.8 \%$ & $43.5 \%$ \\
\hline \multirow[t]{2}{*}{ Other } & Freq. & 9 & 3 & 12 \\
\hline & $\%$ & $18.0 \%$ & $15.8 \%$ & 17.4 \\
\hline \multirow[t]{2}{*}{ Total } & Freq. & 50 & 19 & 69 \\
\hline & $\%$ & $100.0 \%$ & $100.0 \%$ & $100.0 \%$ \\
\hline
\end{tabular}




\begin{tabular}{|l|r|c|c|c|}
\hline \multicolumn{5}{|c|}{ TABLE 3 } \\
\hline & & Not Tenure Track & Tenure Track & Total \\
\hline No Leave Offered & Freq. & 22 & 3 & 25 \\
\hline & $\%$ & $45.8 \%$ & $15.8 \%$ & $37.3 \%$ \\
\hline Leave Offered & Freq. & 26 & 16 & 42 \\
\hline & $\%$ & $54.2 \%$ & $84.2 \%$ & $62.7 \%$ \\
\hline Total & Freq. & 48 & 19 & 67 \\
\hline & $\%$ & $100.0 \%$ & $100.0 \%$ & $100.0 \%$ \\
\hline $\begin{array}{l}\text { Chi-square }=5.253, \mathrm{df}=1, \mathrm{p}=.022 \\
\text { *Excludes responses where the librarian tenure status was classified as “other" }\end{array}$ \\
\hline
\end{tabular}

30 who indicated extended leave is available, 19 had unpaid leave, eight had paid leave, and the remaining three had both paid and unpaid leave. Of those who answered "other," the answers in the order of frequency were that extended leave was available using vacation and/or sick time (5), did not know (4), sometimes (3), and individually negotiated (2). A Chi-square test rejects the null hypothesis that the option for extended leave is independent of tenure status: at a significance level of $p=.005$, institutions that grant tenure to librarians are more likely to offer extended maternity leave to librarians.

The final significant relationship between demographic factors and benefits concerned paid leave of any length for fathers. Again, being employed by an institution that offered tenure to librarians made it more likely that such a policy would be available (see table 3 ). Of the 73 respondents who answered this question, 47 (64\%) represented institutions that offered paid leave to fathers while $26(36 \%)$ did not. (When institutions where respondents listed "other" under tenure status were excluded, the total number was 67 , with 42 , or 63 percent, representing paid leave and 25, or 37 percent, representing no paid leave.) A Chi-square test rejects the null hypothesis that the option for paid paternity leave is independent of tenure status: at a significance level of $p$ $=.022$, institutions that grant tenure to librarians are more likely to offer paid paternity leave to librarians.

\section{Other Results}

Although significant relationships could not be found between demographics and any of the other benefits, the totals and responses to the questions were of interest and are reported below.

Respondents were asked whether the general practices at their institutions regarding time off for pregnancy/childbirth were codified or informal, with FMLA compliance assumed. Of the 81 institutions who answered, most (45, or $56 \%$ ) said policies were codified, 14 (17\%) said only FMLA was offered, and the rest said either they did not know (8, or $10 \%)$, informal arrangements were available $(4$, or $5 \%)$, or "other" $(10$, or $12 \%)$. Some of the "other" responses included:

- Whatever flexibilities are offered by departments beyond what's required by FMLA will be up to the chairs/directors/deans.

- Codified for staff, but the practices for faculty are more flexible.

A similar question was asked regarding adoption; although codified practices were still the most common response (32/80, or $40 \%$ ), the second most commonly given response was "do not know" (19, or 24\%), then "FMLA was all that was offered" (17, or $21 \%$ ), with the remainder evenly split (6, or $8 \%$ each) between informal policies and "other." One of the responses to "other" was "none," which is disturbing, if trueand a violation of FMLA.

Respondents who indicated that librarians at their institution are eligible 
for tenure or answered "other" to that question were asked a series of follow-up questions related to family-friendly tenure policies. The first question was whether tenure clock extension, defined as delaying the tenure process without increasing research expectations, was available to new parents. Of the 29 who answered this question, 17 (59\%) said yes, while 12 $(41 \%)$ said no. Of those who said yes, most (13, or $76 \%$ ) said tenure clock extension was available to both parents, while three $(18 \%)$ said it was only available to the primary caregiver and one $(6 \%)$ only to mothers. These tenure clock stoppage policies were codified at slightly more than half $(10 / 18$, or $56 \%)$ of the respondents' institutions. Most institutions require interested librarian faculty to request a tenure clock extension $(13 / 16$, or $81 \%)$, while at three responding institutions, the extension is automatically granted. The final tenure clock extension question asked how many times the tenure clock could be stopped by one individual upon the birth or adoption of a child. Fifteen people responded, and seven ( $47 \%$ ) said it could only be stopped once; five (33\%) said it could be stopped more than once, but there was a cap; and the remaining three $(20 \%)$ said there was no limit.

Another family-friendly policy offered by some institutions upon the birth or adoption of a child is a modification of duties. This could include working from home either full- or part-time for a period, relief from committee work, or a decrease in instruction, among other possibilities. When asked whether modified duties were offered by their institution, 75 people responded. Most (39, or 52\%) said this was offered informally, some (21, or $28 \%$ ) said it was not offered, and the smallest group $(15$, or $20 \%)$ said such policies were codified. At most institutions, modified duties were available to both parents $(40 / 53$, or $75 \%)$, but eight $(15 \%)$ indicated availability for only the primary caregiver, and five $(9 \%)$ for only the mother. Very few libraries $(2 / 50$, or $4 \%$ ) offering modified duties to new par- ents require them to "pay back" that time by performing extra duties at a later date.

Respondents were asked whether the new parent policies governing librarians differed from those for faculty. Most $(60 / 71$, or $85 \%)$ said no. Some of the explanations given by those 11 (15\%) who answered yes included:

- Faculty can take a term leave as well as most attempt to have their children during the summer.

- The library is separate from our college's faculty and so I do not know what is offered to faculty here. Anecdotally, many faculty schedule a sabbatical to cover bonding leave as new parents. This is not available to librarians here.

- Our practices are different from the 10-month faculty but are consistent with other 12-month faculty and administrators.

- Each leave is negotiated separately so they may vary.

- I don't know-we have a librarian pregnant right now but it's the first time in the 20 years I have been here.

Similarly, respondents were asked whether the new parent policies regarding librarians differed from those for other campus staff. Again, most people (63/71, or $89 \%)$ said no. Of those eight $(11 \%)$ who said yes, explanations included the following:

- Librarians have more flexibility as exempt staff than nonexempt staff.

- Policies for librarians, like all faculty (librarians have faculty status), are very different from those for other staff.

- Staff policies are more codified while faculty policies are somewhat more flexible/negotiable.

Next, respondents were asked whether expectant parents at their institution negotiated their maternity/paternity benefits. Most (47/69, or 68\%) said no, benefits were codified in written format. The next largest group of respondents (12, or $17 \%)$ answered "other," with more than half of 
those indicating they did not know. One person commented, "I do not know if negotiations have taken place. We have had no pregnancies at the library during my tenure. Such negotiations would be confidential." Seven (10\%) responded that benefits are individually negotiated, and three $(4 \%)$ said that benefits were not individually negotiated but an unwritten policy was standardized and followed.

Finally, respondents were asked to offer comments regarding the topic of family-friendly policies for academic librarians. Some of the comments included:

- Although university policies are intended to cover both fathers and mothers, very few new fathers have used this leave. Our policies also cover "qualifying adults," which is typically a domestic partner.

- Campus policies do not begin to go to the level of depth asked in this survey.

- Beyond what is required by FMLA, much of it depends on the department, staffing and operational needs, and willingness of the person in charge to consider additional time off.

- In the 15 years I have worked in this library, no one has requested maternity leave. Hence, my answers are not very helpful.

\section{Discussion}

One of the most interesting findings from this study was that the only statistically significant differences between institutional demographics and the parental policies offered librarians was related to whether librarians were eligible for tenure at those institutions. There were not significant differences found for Carnegie Classification, ${ }^{25}$ public versus private institutions, or institutions where librarians are considered faculty. The last factor was the most surprising. Tenure eligibility affected whether policies were available to librarians in a way that faculty status did not. Perhaps this can be explained by examining the perception by the rest of campus of librarians who hold faculty status without tenure eligibility. These librarians may be perceived more as administrators than actual members of the faculty. Research, publication, and presentation expectations required of tenured and tenure-track librarians may help make the case on campus for truly equitable treatment when it comes to policies available to librarian faculty.

In this study, most respondents (60/71, or $85 \%$ ) indicated that, on their campus, new parent policies governing librarians did not differ from those governing faculty. However, when the results of this study are compared to the University of Michigan national survey, ${ }^{26}$ this supposition is not borne out. Overall, policies available to academic librarians compare negatively to policies available to faculty (see table 4). Academic librarian mothers are less likely to be paid during the period of disability and are less likely to have dependent care leave beyond the period of FMLA than their faculty colleagues. Tenure-track librarians are also less likely to have tenure clock stoppage available to them. Regarding modification of duties, practices are similar between academic librarians and faculty. The only area where academic librarians came out ahead when compared to the University of Michigan study ${ }^{27}$ was paid leave offered to new fathers.

Perhaps some of the difference in the post-FMLA dependent care leaves for mothers between librarians and faculty can be explained by the nature of the jobs. Academic librarians are typically on twelve-month contracts and work fairly regular schedules and have vacation and sick time available. Faculty are typically on nine-month contracts, have more varied hours, and no vacation or sick time available. Thus, because faculty have no vacation or sick time, other alternatives for time off after FMLA must be used, which their more flexible schedules also encourage. Another explanation may be that faculty teach classes within which it can be very disruptive to have to switch instructors 


\section{TABLE 4}

\section{Comparison Between Policies Offered to Academic Librarians and Faculty}

\begin{tabular}{|c|c|c|}
\hline & Academic Librarians & Faculty $^{28}$ \\
\hline $\begin{array}{l}\text { Biological Mothers Paid } \\
\text { During Period of Disability }\end{array}$ & $69 \%$ & $\begin{array}{l}\text { Formally: } 78 \% \\
\text { Formally or Informally: } 91 \%\end{array}$ \\
\hline \multirow[t]{2}{*}{$\begin{array}{l}\text { Dependent Care Beyond } \\
\text { FMLA or Period of } \\
\text { Disability }\end{array}$} & \multirow{2}{*}{$\begin{array}{l}\text { For Mothers Beyond FMLA } \\
\text { Unpaid: } 25 \% \\
\text { Paid: } 11 \% \\
\text { Both Paid and Unpaid: } 4 \% \\
\text { Total Paid and Unpaid: } 39 \% *\end{array}$} & $\begin{array}{l}\text { Unpaid: Either Parent Be- } \\
\text { yond FMLA } \\
\text { Formally: } 44 \% \\
\text { Formally or Informally: } 75 \%\end{array}$ \\
\hline & & $\begin{array}{l}\text { Paid: Biological Mothers } \\
\text { Beyond Period of Disability } \\
\text { Formally: } 29 \% \\
\text { Formally or Informally: } 49 \% \\
\end{array}$ \\
\hline Paid Leave for Fathers & $64 \%$ & $\begin{array}{l}\text { Formally: } 36 \% \\
\text { Formally or Informally: } 42 \%\end{array}$ \\
\hline Tenure Clock Extension & $59 \%$ & $\begin{array}{l}\text { Formally: } 65 \% \\
\text { Formally or Informally: } 83 \%\end{array}$ \\
\hline Modification of Duties & $\begin{array}{l}\text { Formally: } 20 \% \\
\text { Informally: } 52 \%\end{array}$ & $\begin{array}{l}\text { Formally: } 21 \% \\
\text { Formally or Informally: } 63 \%\end{array}$ \\
\hline
\end{tabular}

mid-course. To prevent multiple instructors having to teach a course, some departments may opt to relieve the expectant parent due during the semester/quarter from teaching expectations for that session.

One of the pitfalls of this study was the sample size. Even though 81 people responded to the survey, some chose not to answer certain questions and some questions were not offered to respondents based on their answers to previous questions. Because of this, a portion of the questions, including many of the correlations for Carnegie Classification, had too few responses to conduct a statistically significant Chi-square test. If this study is repeated in the future, a larger sample size will be used.

\section{Conclusion}

There is a lack of substantial literature related to parental policies offered to academic librarians; therefore, there are many areas within this subject needing further exploration. This study focused on benefits available to academic librarians, but it would also be useful to study how many librarians for whom these policies are available take advantage of them. It would also be interesting to see whether, within institutions offering tenure to librarians, there is a significant difference between the numbers of tenured librarians taking advantage of available benefits versus those who are not yet tenured. The University of Michigan group conducted two studies separated by five years and found that policies offered had improved during the interim, ${ }^{29}$ it would be informative to repeat the academic librarian study in the future to see if policies for librarians also improve over time.

This study showed that tenured and tenure-track librarians have more generous parental policies available to them than other types of librarians, even those with faculty status. Future studies could explore whether these more generous policies for tenure-track librarians extend to other types of benefits. This finding also gives librarians at tenure-track libraries a reason to safeguard that status, and those at libraries that do not offer tenure a reason to push to make tenure available.

Finally, it is important to remember that benefits, including those related to 
childbirth and childcare, can go a long way to improving job satisfaction. As stated by Stockdell-Giesler and Ingalls, "when we put pregnancy and childbirth into the context of the typical faculty career, a semester-long maternity leave is a mere blip on the screen of a commitment to an institution that often spans decades." ${ }^{30}$ The same argument can be made for academic librarians.

\section{Notes}

1. Mickey Zemon and Alice Harrison Bahr, "Career and/or Children: Do Female Academic Librarians Pay a Price for Motherhood?" College \& Research Libraries 66, no. 5 (Sept. 2005): 394.

2. Stephanie J. Graves, Jian Anna Xiong, and Ji-Hye Park, "Parenthood, Professorship, and Librarianship: Are They Mutually Exclusive?" Journal of Academic Librarianship 34, no. 3 (May 1, 2008): 203-04.

3. Ibid., 202.

4. Ibid., 204.

5. Ibid., 208.

6. Zemon and Bahr, "Career and/or Children," 394-405.

7. Ibid., 400 .

8. University of Michigan Center for the Education of Women, Family-Friendly Policies in Higher Education: A Five-Year Report (Dec. 2007): 1-28, available online at www.cew.umich.edu/ sites/default/files/ReduxBriefFinal5-1.pdf [accessed 31 October 2011].

9. Ibid., 5 .

10. Ibid., 18.

11. Ibid., 17.

12. American Association of University Professors, Statement of Principles on Family Responsibilities and Academic Work, approved in 2001: 219, available online at www.aaup.org/NR/ rdonlyres/42720A36-CCC4-4FFE-852E-D9CFA5F66D7C/0/StatementofPrinciplesonFamilyResponsibilitiesandAcademicWorkcademic.pdf [accessed 31 October 2011].

13. Ibid., 221.

14. Ibid., 221-23.

15. Ibid., 222.

16. Zemon and Bahr, "Career and/or Children," 400; Graves, Xiong, and Park, "Parenthood, Professorship, and Librarianship," 206; Delores D. Liston, Marlynn M. Griffin, and Jeanette M. Hecker, "Living with the Family Leave Act of 1993: Case Studies of Women in Academe" (Mar. 1997): 17, ERIC, ED 411720; Anne Stockdell-Giesler and Rebecca Ingalls, "Faculty Mothers," Academe 93, no. 4 (July 1, 2007): 3.

17. Robert Drago et al., "The Avoidance of Bias Against Caregiving: The Case of Academic Faculty," American Behavioral Scientist 49, no. 9 (2006): 1223.

18. Ibid., 1225.

19. AAUP, "Statement on Principles on Family Responsibilities," 223; University of Michigan Center for the Education of Women, Family-Friendly Policies, 27; Graves, Xiong, and Park, "Parenthood, Professorship, and Librarianship," 203; Stockdell-Giesler and Ingalls, "Faculty Mothers," 3.

20. Joseph Untener, "From Conception through Delivery: Developing a Just and Equitable Faculty Maternity Leave Policy," CUPA-HR Journal 59, no. 1 (Mar. 2008): 42.

21. Ibid., 45.

22. Carnegie Foundation for the Advancement of Teaching, 2010 Classification of Institutions of Higher Education, available online at http://classifications.carnegiefoundation.org/descriptions/ basic.php [accessed 31 October 2011].

23. University of Michigan Center for the Education of Women, Family-Friendly Policies, 1-28.

24. U.S. Department of Labor, Leave Benefits, available online at www.dol.gov/dol/topic/ benefits-leave/fmla.htm [accessed 31 October 2011].

25. For many of the results broken down by Carnegie Classification, the sample size was too small to find significance (more than 20 percent of the expected values were less than five). Because there were more categories within Carnegie Classification than the other demographic variables (producing smaller expected values per cell), fewer results within this variable had the possibility of being significant.

26. University of Michigan Center for the Education of Women, Family-Friendly Policies, 17-18.

27. Ibid.

28. University of Michigan Center for the Education of Women, Family-Friendly Policies, 17-18.

29. Ibid., 1.

30. Stockdell-Giesler and Ingalls, "Faculty Mothers," 6. 